\title{
Producción y evaluación de la calidad nutricional del forraje verde hidropónico (FVH) a base de maíz (Zea mays) como alternativa para la alimentación de pollos de engorde en la Estación Ambiental Tutunendo, Chocó, Colombia
}

\section{Production and evaluation of the nutritional quality of forraje verde hidropónico (FVH) with maize (Zea mays) as alternative for the feeding of chickens of fattening in the Estación Ambiental Tutunendo, Chocó, Colombia}

\author{
Teófilo Cuesta Borja ${ }^{1}$, Rosmery Machado Perlaza ${ }^{2}$

\section{RESUMEN}

El forraje verde hidropónico (FVH) es una tecnología de producción de biomasa vegetal que se basa en el crecimiento de las plantas en los estados de germinación y crecimiento temprano de plántulas a partir de semillas viables. Al tratar de desarrollar una alternativa de alimentación de pollos de engorde en la Estación Ambiental Tutunendo se evaluó la calidad nutricional del forraje verde hidropónico a base de maíz chococito (Zea mays). Para el desarrollo de la investigación, se cumplieron cinco fases: en la primera se construyó y adecuó un invernadero; en la segunda fase se prepararon las semillas de maíz; la tercera consistió en el establecimiento y manejo del sistema; en la cuarta fase se realizaron las evaluaciones de campo y en la quinta fase se adelantó el análisis bromatológico de las muestras en el ámbito de laboratorio y análisis de resultado. Se logró una viabilidad de las semillas de maíz del orden de $87 \%$ y se comprobó que el mejor tratamiento se logra a los 12 días de cosecha, cuando se registra el mejor balance nutricional del forraje en su contenido de proteína, grasa y macronutrientes, adecuado para la alimentación de pollos de engorde.

Palabras clave: Forraje verde hidropónico; Nutrición animal; Maíz chococito; Pollos de engorde; Análisis bromatológico.

\begin{abstract}
The hydroponic green forage $(F V H)$ is a technology of production of vegetal biomass from the growth of the plants in the states of germination and early growth of plántulas from viable seeds. Looking for to develop an alternative of feeding of chickens of fattening in the Estacion Ambiental Tutunendo the nutritional quality of the hydroponic green forage with chococito maize (Zea mays) For the development of the investigation was evaluated, were fulfilled five (5) phases; first it consisted of constructing and adapting a greenhouse; in the second phase the preparation of the maize seeds occurred; third it consisted of the establishment and handling of the system; the fourth phase was for the field evaluations and in the fifth phase the bromatologico analysis of the samples in the scope of laboratory and analysis of result was realised. A viability of the maize seeds of the order of $87 \%$ was obtained and it was verified that the best treatment is obtained to the 12 days of harvest, time in which the best nutritional balance of the forage in its content of protein, fat is registered andmacronutrients; adapted for the feeding of chickens offattening.
\end{abstract}

(C) Instituto de Investigaciones Ambientales del Pacífico «John Von Neumann»
1. Ingeniero Agrónomo. Docente, Universidad Tecnológica del Chocó, Quibdó, Colombia.e-mail: tcuesta@ hotmail.com

2. Ingeniera Agroforestal, Universidad Tecnológica del Chocó, Quibdó, Colombia. Recibido: Junio 8, 2009

Aceptado: Junio 17, 2009 


\section{Bioetnia Volumen 6 № 2 (julio-diciembre), 2009}

Keywords: Hydroponic green forage; Nutrition animal; Chococito maize; Chickens of fattening; Bromatologic analysis.

\section{INTRODUCCCIÓN}

El forraje verde hidropónico (FVH) es una tecnología de producción de biomasa vegetal obtenida a partir del crecimiento inicial de las plantas en los estados de germinación y crecimiento temprano de plántulas con base en semillas viables. El FVH es un forraje vivo, de alta digestibilidad, calidad nutricional y muy apto para la alimentación animal. En la práctica, el FVH consiste en la germinación de granos (semillas de cereales o de leguminosas) y su posterior crecimiento bajo condiciones ambientales controladas (luz, temperatura y humedad) en ausencia del suelo. Por lo general se utilizan semillas de avena, cebada, maíz, trigo y sorgo.

La producción del FVH es tan sólo una de las derivaciones prácticas que tiene el uso de la técnica de los cultivos sin suelo o hidroponía y se remonta al siglo XVII cuando el científico irlandés Robert Boyle (1627-1691) realizó los primeros experimentos de cultivos en agua. Pocos años después, John Woodward produjo germinaciones de granos utilizando aguas de diferentes orígenes y comparó diferentes concentraciones de nutrientes para el riego de los granos así como la composición del forraje resultante (Huterwal 1960, Ñíguez 1988).

Dentro del contexto anterior, el FVH representa una alternativa de producción de forraje para la alimentación de cabras, terneros, vacas en ordeño, caballos, conejos, pollos, gallinas ponedoras, patos y cuyes entre otros animales domésticos, y sobre todo útil durante períodos de escasez de forraje verde.

En países como Costa Rica, en especial en la Meseta Central donde el precio de la tierra alcanza niveles muy altos, la idea de una «fábrica de pastos» mediante el uso de la hidroponía, es una genialidad para muchos pequeños y medianos productores pecuarios, porque con un pequeño invernadero donde se pusieron a germinar y crecer en bandejas cientos de semillas de maíz, avena, cebada, trigo o alfalfa se obtuvo en un tiempo record de 12 a 15 días todo el forraje verde que se necesita para alimentar el ganado caprino, bovino, ovino o porcino (Castro 2004).

De otra parte, en Colombia la alimentación convencional de gallinas es a base de concentrados industriales, lo que afecta la rentabilidad del sistema pecuario, por los altos costos de éste en la localidad; de igual forma, es importante mencionar que existen también diferentes alternativas para la alimentación de gallinas, unas más eficientes que otras. Por lo anterior, es necesaria la búsqueda de alternativas proteicas de origen vegetal que ayuden a solventar la deficiencia de este importante componente para la nutrición animal, para así reducir el nivel de incorporación de insumos costosos en los sistemas agropecuarios, a través de la producción del FVH),
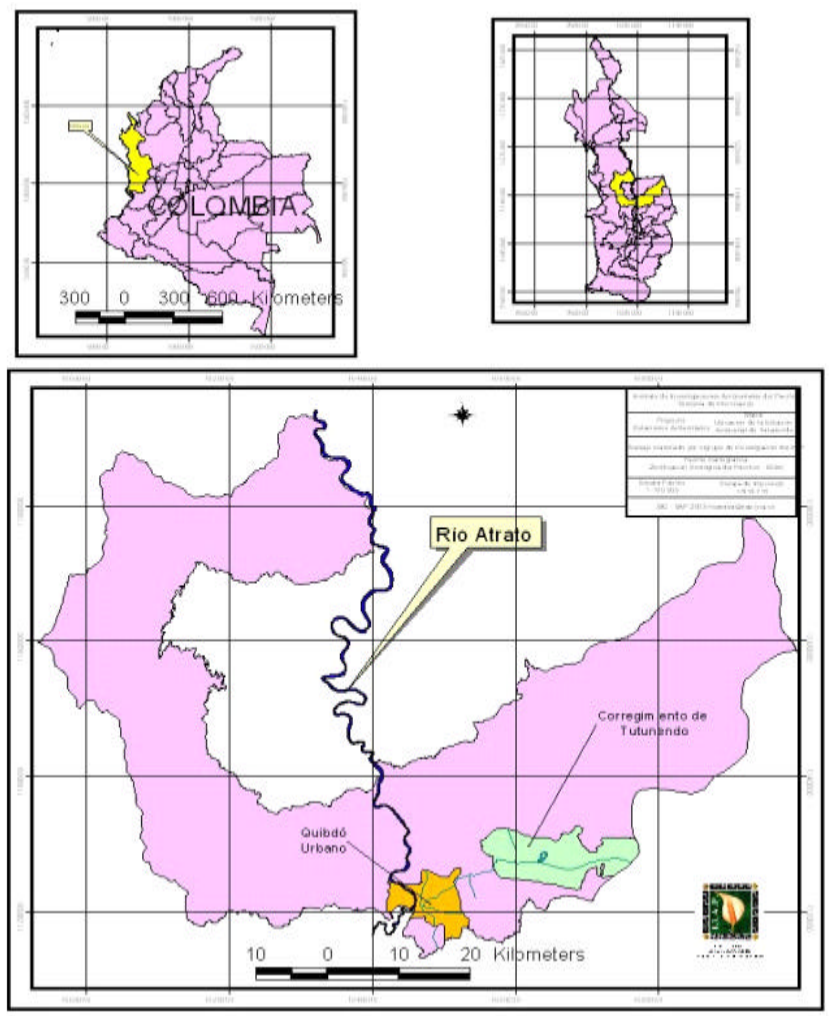

Figura 1. Ubicación geográfica de la Estación Ambiental de Tutunendo

que consiste en la germinación de cereales como el maíz, sorgo, arroz, cebada, trigo, en un invernadero climatizado con riego permanente mediante el uso de bandejas plásticas a diferentes niveles sobre estantes, teniendo una producción constante de forraje fresco, compuesto de raíz, tallo y hojas, a una altura de $30 \mathrm{~cm}$, durante todo el año, para suplementar la alimentación de vacas lecheras, caballos, cabras, cerdos, conejos, aves de corral, cachamas, etc. Con esta técnica se reemplazan a muy bajo costo los concentrados con una proporción económica de 50\% (Rincón 2002). En virtud de lo anterior surge esta investigación, con la que se pretende validar un modelo de producción de FVH a base de maíz (Zea Mays), al tiempo que se evalúa la calidad nutricional del mismo, en aras de validar una alternativa para la alimentación de pollos de engorde en la Estación Ambiental Tutunendo.

\section{ÁREA DE ESTUDIO}

Ubicación geográfica. La Estación Ambiental Tutunendo (EAT) está localizada en el corregimiento que lleva su mismo nombre, a la altura del kilómetro 16 de la vía nacional que conduce de la capital del Chocó (Quibdó) a Medellín. La estación abarca una extensión de 80.72 ha; se ubica entre los $5^{\circ} 45^{\prime}$ y $5^{\circ} 46^{\prime}$ de latitud norte y los $76^{\circ} 30.5^{\prime}$ y $76^{\circ} 31.51^{\prime}$ de longitud oeste (Abadía et al. 2002) (Figura 1). 

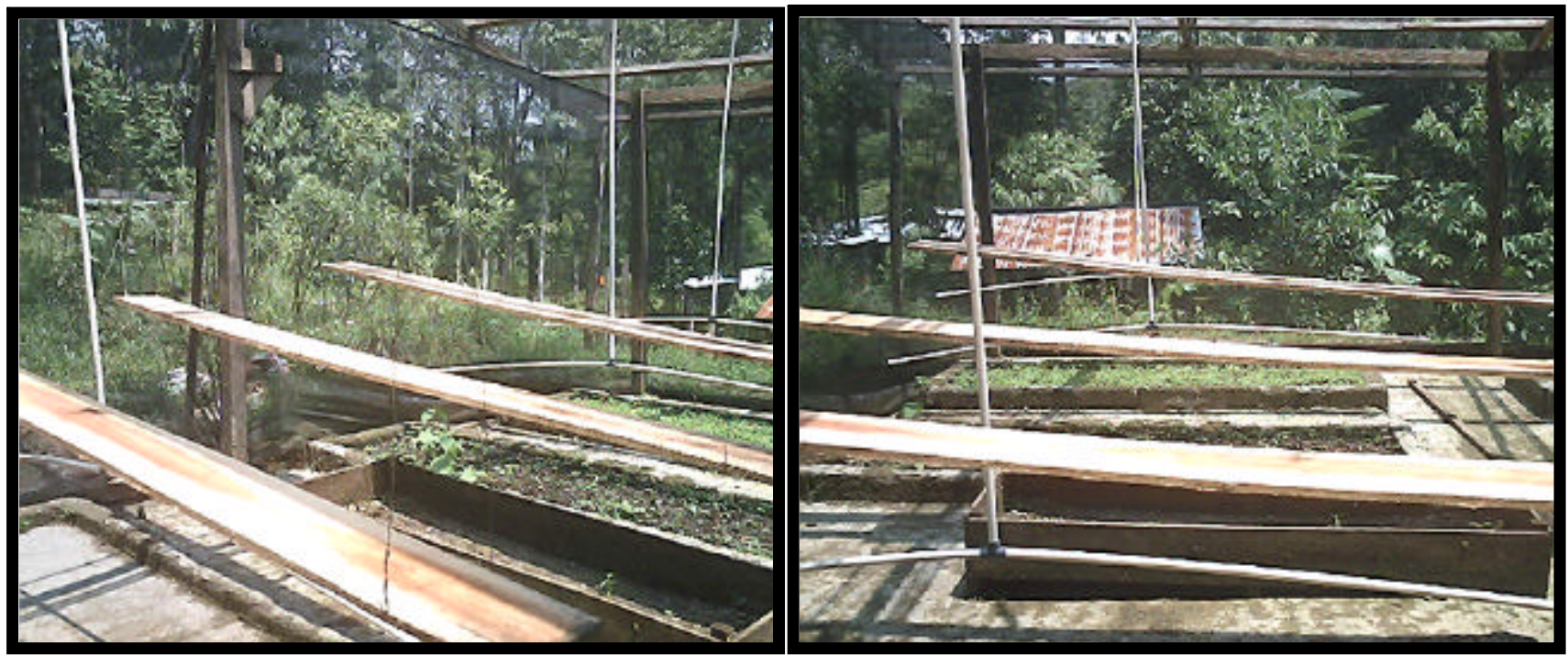

Figura 2. Vista diagonal del invernadero.

Este corregimiento hace parte del Chocó biogeográfico y en su extensión alberga gran parte de su biodiversidad; por ser un bosque pluvial húmedo, posee una gran diversidad biológica y cultural, reconocida en el ámbito nacional e internacional (Minga IIAP 2001). Cuenta con una precipitación de $11.700 \mathrm{~mm} / \mathrm{año}$, su temperatura es $27^{\circ} \mathrm{C}$ y la humedad relativa de $87 \%$, condiciones que corresponden a la formación bosque húmedo pluvial tropical (bh-PT) según la clasificación de zonas de vida de Holdridge. El clima es húmedo y cálido (Job de Wilde 1999).

\section{MÉTODOS}

Esta investigación se llevó a cabo en cinco fases: en la primera se construyó y adecuó un invernadero, en la segunda fase se prepararon las semillas de maíz, la tercera consistió en el establecimiento y manejo del sistema, en la cuarta fase se realizaron las evaluaciones de campo, la quinta fase se adelantó el análisis bromatológico de las muestras en el ámbito de laboratorio, y por último, la sexta fase se dedicó al análisis de resultados, tal como se detalla a continuación.

Fase 1. Construcción y adecuación de invernadero. En este caso se adecuó un invernadero, que se cerró por completo con malla metálica y madera, dejando una puerta de acceso donde se tuvieran unas condiciones óptimas que le permitiera a la semilla seguir su proceso normal de crecimiento, sin que fuera atacada por roedores o pájaros. Sus dimensiones fueron de $3 \mathrm{~m}$ de ancho $\mathrm{x} 4 \mathrm{~m}$ de largo, dejando espacios de 1 metro para corredores.

El invernadero se equipó con tres módulos de producción, que constaban de 10 pisos separados unos $40 \mathrm{~cm}$ entre sí, con ángulos de inclinación en forma de zigzag. Su diseño debe ser de tal forma que soporte las bandejas hasta el momento de la cosecha (10-15 días); para este caso se pensó en estantes de madera (Figura 2).

Fase 2. Preparación de semillas. Esta fase incluye cuatro subfases, a saber: selección de las especies a cultivar, selección, lavado y remojo de las semillas, tal como se detalla a continuación:

Selección de las especies de granos utilizados en FVH. Se decidió utilizar granos de maíz chocosito, por la disponibilidad local de este grano.

Selección de la semilla. Durante esta subfase se tuvo el cuidado de seleccionar semillas de buena calidad, de origen conocido, adaptadas a las condiciones locales, disponibles y de probada germinación y rendimiento.

Lavado de la semilla. Las semillas se lavaron y desinfectaron con una solución de hipoclorito de sodio al $1 \%$, que se preparó diluyendo $10 \mathrm{ml}$ de hipoclorito de sodio por cada litro de agua. El lavado se hizo con el objeto de eliminar hongos y bacterias contaminantes, liberarlas las semillas de residuos y dejarlas bien limpias (Rodríguez et al. 2000). El desinfectado con el hipoclorito elimina prácticamente los ataques de microorganismos patógenos al cultivo de $\mathrm{FVH}$. El tiempo de remojo de las semillas en la solución de hipoclorito fue de un minuto, porque si se dejaba más tiempo podría perjudicar su viabilidad, causando importantes pérdidas de tiempo y dinero; finalizado el lavado se procedió a un enjuague riguroso de las semillas con agua limpia.

Remojo y germinación de las semillas. Esta etapa consistió en colocar las semillas dentro de una bolsa de tela y sumergirlas por completo en agua limpia por un período no mayor a 24 horas para lograr una completa imbibición. Este tiempo se dividió a su vez en dos períodos de 12 horas cada 


\section{Bioetnia Volumen 6 № 2 (julio-diciembre), 2009}

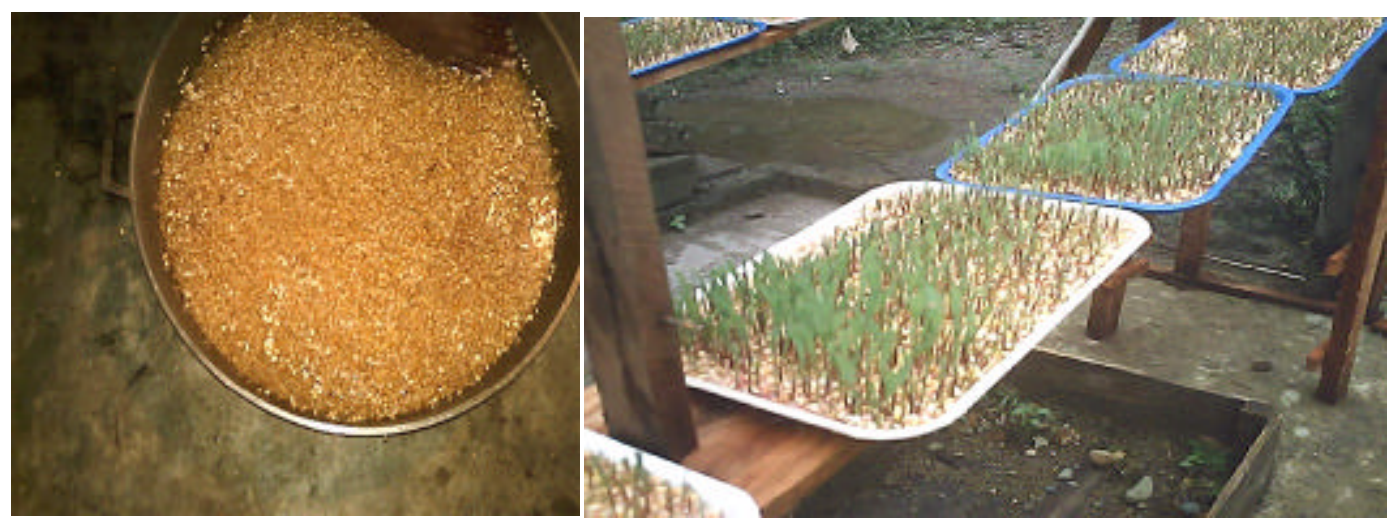

Figuras 3. Remojo y germinación de las semillas.
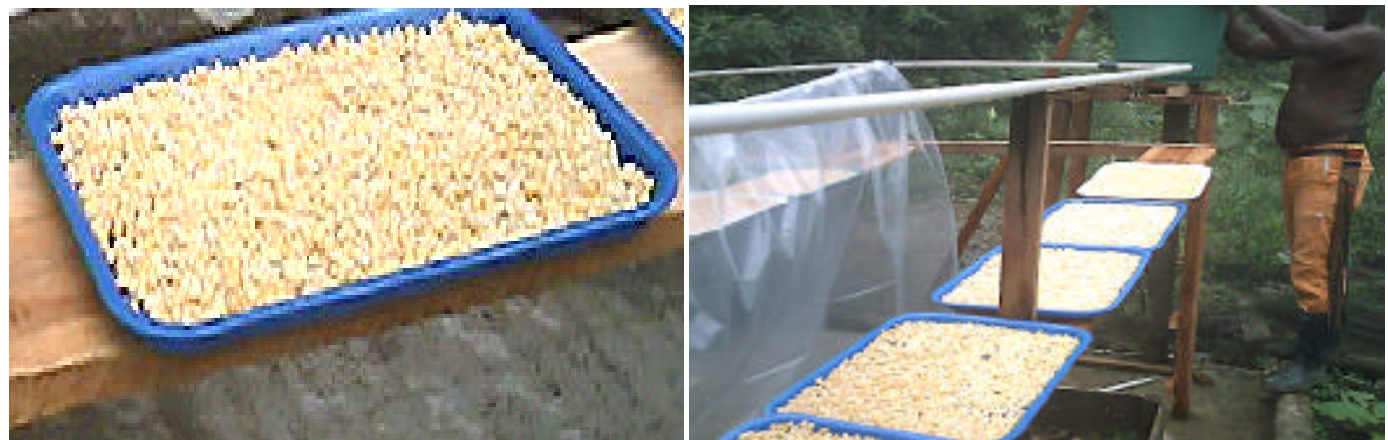

Figura 4. Dosis de siembra en bandejas dispuestas en los estantes.

uno; a las 12 horas de estar las semillas sumergidas se procedió a sacarlas y orearlas (escurrirlas) durante una hora aproximadamente. Después se sumergieron de nuevo por 12 horas para luego realizar el último oreado. Mediante este fácil proceso se indujo la rápida germinación de la semilla, a través del estímulo efectuado a su embrión. Esta pregerminación asegura un crecimiento inicial vigoroso del $\mathrm{FVH}$, porque sobre las bandejas de cultivo se utilizaron semillas que ya habían brotado y por tanto su posterior etapa de crecimiento estuvo más estimulada. El hecho de cambiar el agua cada 12 horas facilita y ayuda a una mejor oxigenación de las semillas (Figura 3).

Fase 3. Establecimiento y manejo el sistema. Para el establecimiento del sistema se definieron tres tratamientos: el primero (T1), contó con cuatro bandejas (repeticiones), que se cosecharon a los 10 días; el segundo tratamiento (T2), contó con el mismo número de bandejas y se cosechó a los 12 días; por último, el tercer tratamiento (T3) se cosechó a los 15 días. La lógica de estos tratamientos fue la determinación del tiempo óptimo de cosecha, es decir, el momento en que se obtiene la mayor producción de biomasa vegetal y calidad nutricional del forraje.

Dosis de siembra. Las dosis óptimas de semillas a sembrar por metro cuadrado oscilan entre 2.2 kilos a 3.4 kilos considerando que la disposición de las semillas o «siembra» no debe superar $1.5 \mathrm{~cm}$ de altura en la bandeja (Figura 4).

Siembra en las bandejas e inicio de los riegos. Realizados los pasos previos, se procedió a la siembra definitiva de las semillas en las bandejas de producción. Para ello se distribuyó una delgada capa de semillas pregerminadas, que no sobrepasó $1.5 \mathrm{~cm}$ de altura o espesor.

Riego de las bandejas. El riego de las bandejas de crecimiento del FVH se realizó a través de un sistema artesanal que consiste en un balde elevado, al que se le acoplaron varios tubos de PVC con micro perforaciones que facilitaban un riego por goteo permanente a las bandejas del sistema. Según cálculos durante el proceso, al comienzo (primeros cuatro días) se aplicaron alrededor de 0.5 litros de agua por metro cuadrado por día hasta llegar a un promedio de 0.9 a 1.5 litros por metro cuadrado. Un indicador práctico que se debe tener en cuenta es no aplicar riego cuando las hojas del cultivo se encuentran levemente húmedas al igual que su respectiva masa radicular (Sánchez 1997) (Figura 5).

Fase 4. Evaluaciones en campo. Las evaluaciones en campo se realizaron de manera sistemática cada dos días, con el objeto de monitorear altura de las plántulas y estado sanitario de las mismas. Al momento de la cosecha se tomó el peso total fresco del FVH y por separado la biomasa aérea (tallo-follaje) y la biomasa subterránea (raíces). Estas mediciones se hicieron de manera sistemática cada dos días; estos 

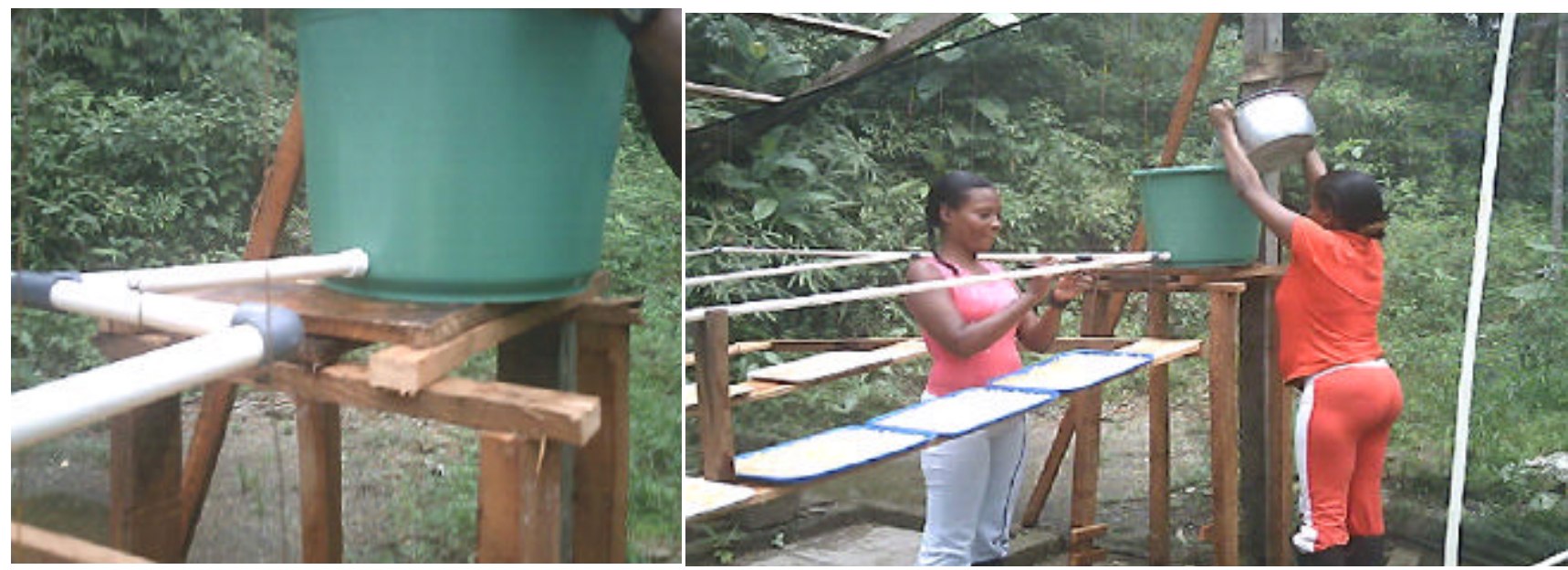

Figura 5. Sistema de riego artesanal.

datos se administraron e integraron a una base de datos para su evaluación final después de cada ciclo productivo.

Fase 5. Análisis bromatológico. Para determinar el porcentaje de proteínas, humedad, ceniza, grasa, fibra, macro y micro elementos que contiene el FVH del maíz chocosito; se tomaron muestras al azar de alrededor de $500 \mathrm{~g}$ de cada tratamiento, luego se procedió a mezclarlas bien y dividirlas en cuatro fracciones, se escogieron dos de éstas, y volviéndose volvieron a mezclar, para al final dividir éstas en cuatro partes y tomar de esta última división más o menos $250 \mathrm{~g}$, que se empacaron en bolsa de plástico con sello hermético, etiquetadas con su respectiva información. Por último, se trasladó el producto resultante de cada tratamiento a los laboratorios de análisis químico de la Universidad de Antioquia, sede Medellín, donde se determinó su composición nutricional. El forraje (raíz, tallo y hojas) se analizó por separado, para determinar cuál contenía mayor valor nutricional. Cabe aclarar que las determinaciones de materia seca, cenizas, proteína y fibra cruda se realizaron siguiendo las normas de la AOAC (1995).

\section{ANÁLISIS DE RESULTADOS}

Se aplicó un diseño por completo aleatorio, se utilizaron dos repeticiones de cada tratamiento, para posibilitar el cálculo de error experimental y poder concluir los resultados obtenidos, donde se tuvo como unidad experimental 12 bandejas de las que se extrajeron las muestras. De igual manera se utilizaron métodos estadísticos tales como la prueba no paramétrica aplicando el método de Kruskal-Wally, para verificar la diferencia entre tratamientos y la prueba de Mann Wine, para verificar la diferencia entre los dos tipos de biomasa (aérea y subterránea) utilizando el programa Spss versión 12 para Windows.

\section{RESULTADOS Y DISCUSIÓN}

Producción de forraje verde hidropónico (FVH). La germinación total del maíz chocosito, fue de $87 \%$ y se obtuvo 0.5 kilo de forraje hidropónico por bandeja; no obstante estos resultados, Castro (2004) reporta con maíz blanco germinación de $10 \%$ y dos kilos de forraje hidropónico por bandeja, lo que se podría explicar por la variedad del maíz utilizado, porque mientras que en este estudio se utilizó un maíz criollo con granos pequeños, Castro utilizó un maíz mejorado con granos grandes, lo que habría permitido la producción de plantas más vigorosas y por tanto con mayor peso.

En cuanto a la cosecha del FVH, el tratamiento 1 se dio a los 10 días con una altura promedio de $18 \mathrm{~cm}$; el tratamiento 2 a los 12 días con altura promedio de $25 \mathrm{~cm}$, lo que coincide con lo reportado por (Rincón 2002), quien indica que entre los 10 y 12 días se podrían obtener hasta $27 \mathrm{~cm}$ en las plántulas de maíz; por último, el tratamiento 3 se cosechó a los 15 días con una altura promedio de $30 \mathrm{~cm}$. Cabe aclarar que los resultados en la obtención de FVH pueden variar dependiendo de las condiciones climáticas de la zona (Figura 6).

Análisis bromatológico. Los datos presentados en la Tabla 1, muestran que el FVH a base de maíz, es más rico nutricionalmente en la biomasa aérea (tallo y follaje) que en la biomasa subterránea (raíces); la misma tabla muestra que el tratamiento 2 (T2) arrojó mejores resultados en el laboratorio en cuanto a porcentaje de proteína bruta, lo que se podría explicar por el hecho de que en el día 10 (cosecha del T1), las plántulas de maíz no han alcanzado su potencial nutritivo mientras se encuentran en desarrollo, en tanto que en el día 15 (cosecha del T3), las plántulas han empezado su proceso de lignificación, es decir, la producción de lignina, sacrificando con ello el contenido proteico. Estos resultados son similares a los reportados por Rincón (2002), quien dice que 

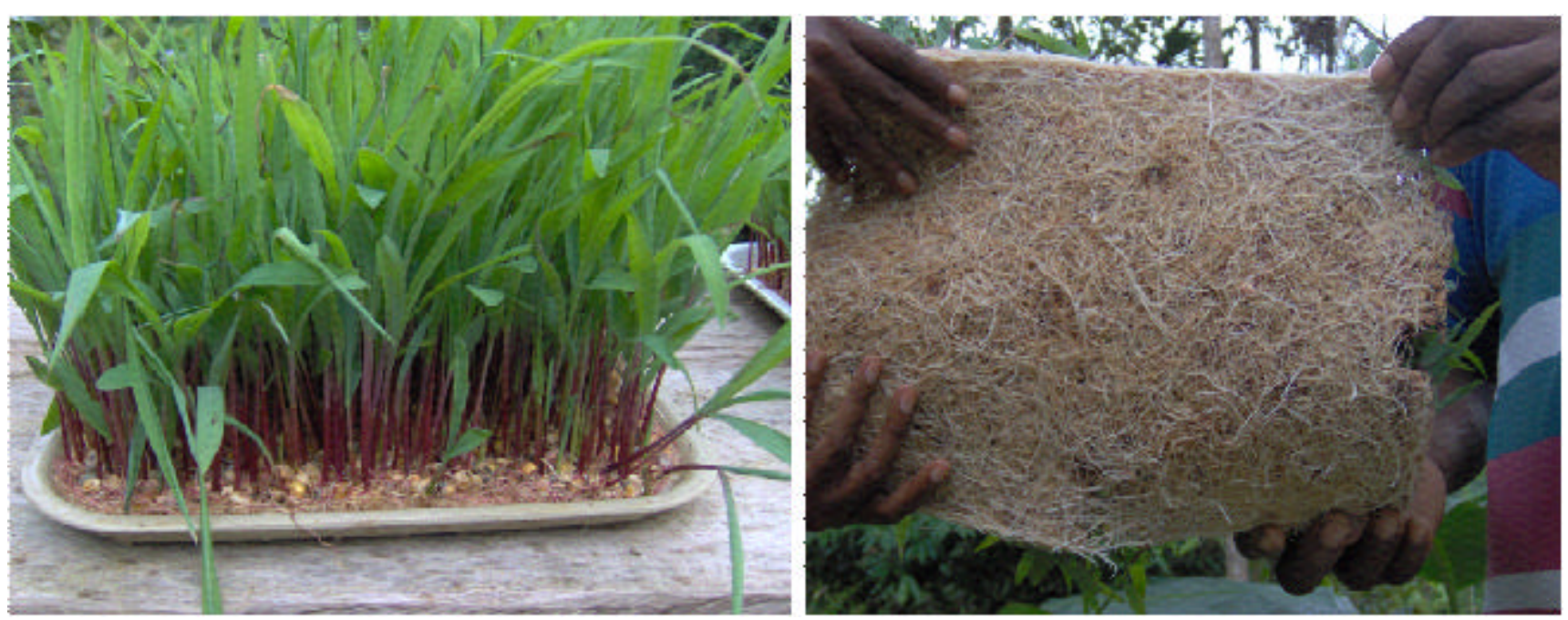

Figura 6. Ilustración del FVH lista para cosechar y tapete de FVH formado por el cruzamiento de raíces.

Tabla 1

Caracterización bromatológica del FVH a base de maíz chocosito

\begin{tabular}{|c|c|c|c|c|c|c|}
\hline \multirow[t]{3}{*}{ Análisis realizados } & \multicolumn{6}{|c|}{ Tratamientos } \\
\hline & \multicolumn{2}{|c|}{ T1 (10 días) } & \multicolumn{2}{|c|}{ T2 (12 días) } & \multicolumn{2}{|c|}{ T3 (15 días) } \\
\hline & Raíces & Follaje & Raíces & Follaje & Raíces & Follaje \\
\hline Cenizas (\%) & 2,2 & 3,8 & 1,9 & 3,6 & 2,1 & 3,6 \\
\hline Calcio (\% Ca) & 0,2 & 0,1 & 0,1 & 0,2 & 0,2 & 0,2 \\
\hline Fósforo (\% P) & 0,2 & 0,2 & 0,1 & 0,2 & 0,1 & 0,2 \\
\hline Energía bruta (kcal/kg) & 4414 & 4524 & 3853 & 4536 & 4153 & 4442 \\
\hline Grasa (\%) & 7.0 & 2,8 & 3,6 & 3,2 & 3,7 & 3,5 \\
\hline Fibra cruda (\% FC) & 11.0 & 21,9 & 29,3 & 30,0 & 11,4 & 30,3 \\
\hline Materia seca total (\% MST) & 28,7 & 13,7 & 14,7 & & & \\
\hline Proteína bruta (\% PB) & 15,3 & 27.0 & 15,2 & 29,6 & 14,3 & 27,1 \\
\hline Peso seco final $(\mathrm{g})$ & 46,15 & 12,22 & 44,80 & 11,94 & & \\
\hline
\end{tabular}

después de los 12 días de establecido el FVH de maíz, este empieza su descenso nutritivo. En otras palabras, teniendo en cuenta que la proteína cruda es uno de los elementos más importantes en la nutrición animal, es posible asegurar con base en los resultados de este estudio, que el tiempo óptimo de cosecha del FVH a base de maíz chocosito es de 12 días.

En la Tabla 1 anterior se observa, un porcentaje considerable de fibra con valores en raíces de $(11 \%, 29.3 \%$ y $11.4 \%)$ y en follaje de $(21.9 \%, 30 \%$ y $30.2 \%)$; lo que coincide con lo reportado por Rodríguez y Tarrillo (2003), quienes reportan valores entre $12-25 \%$ para el mismo cereal.

Con base en estos resultados sobre la fibra, se puede decir que el tratamiento 2 presentó el mayor contenido de fibra cruda, lo que sugiere que este forraje del T2 no sería el más adecuado para la alimentación de pollos de engorde, porque estos no tienen la capacidad de digerir de manera adecuada la celulosa asociada con las fibras (Torrijos 1976); sin embargo, tomando en cuenta que este forraje es rico en otros elementos quizá más importantes en la nutrición animal, la alta concentración de fibra no sería inconveniente para utilizarlo en la alimentación de pollos de engorde.

De igual manera, se encontró un significativo porcentaje de grasa (extracto etéreo) en raíces de $(6.9 \%, 3.6 \%$ y $30.7 \%)$ y en follaje de $(2.8 \%, 3.2 \%$ y $3.5 \%)$, lo que concuerda con los datos informados por Tarrillo (2002), quien reporta valores de la misma especie de FVH entre 2.8-5.4\%. 


\section{Calidad nutricional del forraje verde hidropónico. T Cuesta, R Machado}
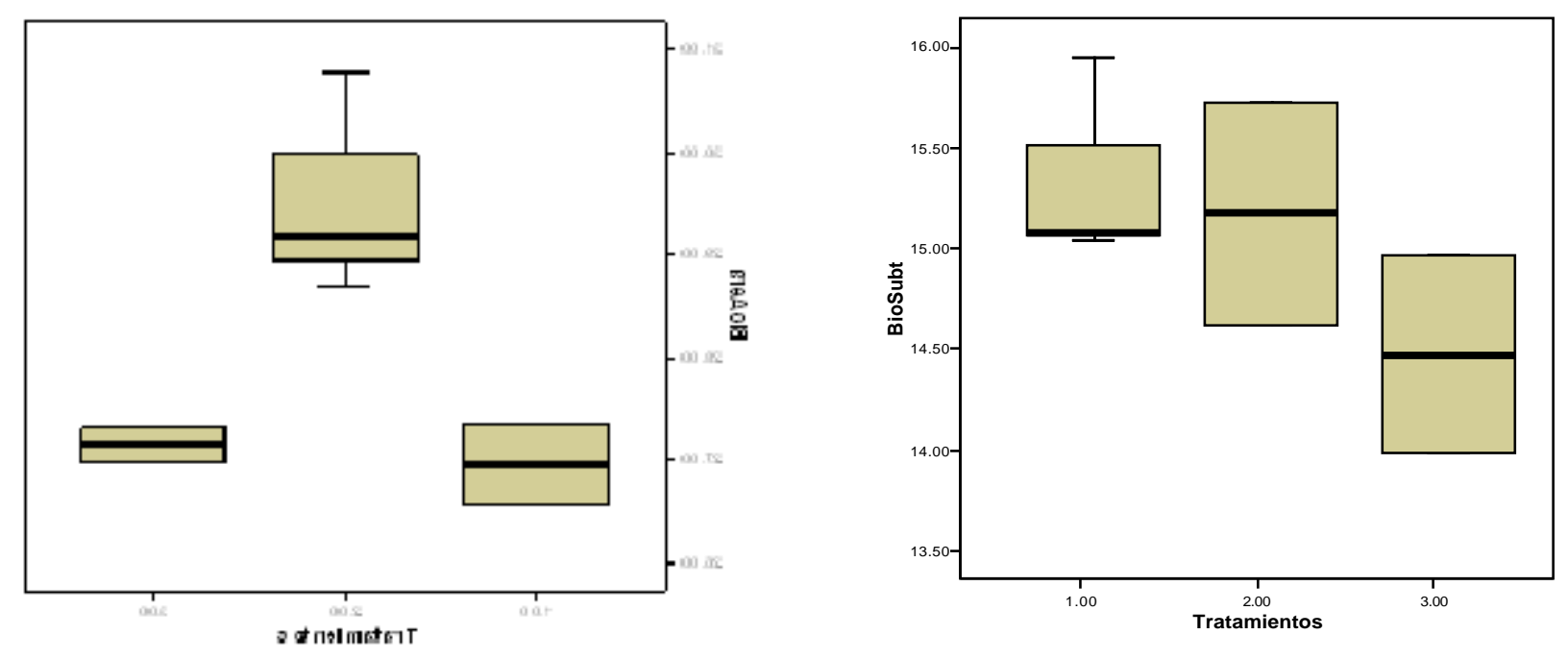

Gráfica 1. Diferencia de biomasa aérea por tratamientos y subterránea.

El tratamiento 1 (T1) se encontró mayor contenido de grasa en la parte de raíz, a diferencia de los tratamientos 2 y 3 donde se comportó de forma muy similar. Así pues, este forraje se puede suministrar a los pollos de engorde durante la etapa de crecimiento, porque es en esta etapa donde los pollos necesitan de la energía para mantener su calor corporal y permanecer saludables.

De forma consecutiva, se detectaron cantidades considerables de macro nutrientes como calcio y fósforo importantes en el FVH estudiado, con valores porcentuales en raíces de Ca: $(0.19,0.11$ y 0.19$)$ y P: $(0.15,0.14$ y 0.14$)$ y en follaje de Ca: $(0.13,0.19$ y 0.19$)$ y $\mathrm{P}:(0.19,0.16$ y 0.18$)$; en este sentido, Carballido (2005), reporta valores similares en cuanto al Ca de 0.10 y mayores valores en cuanto al $\mathrm{P}$ de 0.48 . Contenido de calcio en follaje de 0.32 y en raíz de 0.23 , muestran que no se está muy lejos de lo mencionado (Espinosa y Argenti 2004).

Se puede decir que el contenido de calcio, aunque se comportó con buenos porcentajes en el tratamiento 3 (T3), en la raíz y en el follaje de la planta, también se pueden considerar buenos valores los de los tratamientos 1 y 2 . En este sentido, el calcio es muy importante en la etapa de crecimiento (joven) porque una deficiencia de este elemento provocaría deformaciones que luego afectarán las extremidades vertebrales del animal (Jasca 1987).

Teniendo en cuenta la figura anterior, se puede decir que el porcentaje de fósforo fue mayor en el tratamiento 1, en el follaje de la planta con respecto a los tratamientos 2 y 3 . Así, el fósforo, por su importante contribución a la producción de carne es muy recomendado durante la etapa de crecimiento, pues de lo contrario se vería reflejado en el desarrollo de sus huesos.

Por último, se obtuvo un importante porcentaje de proteína bruta en raíces de $(15.3 \%, 15.1 \%$ y $14.3 \%)$ y en follaje de
$(26.9 \%, 29.5 \%$ y $27.1 \%$ ), en el FVH del maíz chocosito; lo que está dentro de los rangos reportados por (Carballido 2005) quien obtuvo un valor de $18.8 \%$ de proteína en maíz. Los resultados obtenidos en esta investigación en porcentaje de proteína bruta son más altos que los reportados por (Tarrillo 2002), quien reporta valores de 13-20\%.

Este resultado se puede comparar con Rincón (2002) quien reporta que en el día 12 de cosecha (en este caso el T2) la proteína aumenta, pero después de este tiempo empieza un descenso proteico del forraje.

Las necesidades proteicas para los diferentes fines de producción son distintas, pues las aves en crecimiento necesitan más proteínas por tratarse de las primeras fases de la vida, cuando crecen con mayor rapidez. En la etapa inicial de 0-4 semanas ha de ser de 23-29\% (Torrijos 1976), es decir que el tratamiento 1 y 2 en la parte de follaje es el más recomendado para esta etapa. Durante el segundo período de vida (madurez) es importante suministrar raciones más bajas del orden de $21 \%$, de manera que el tratamiento 1 sería el más adecuado para esta etapa.

La prueba de Kruskal-Wallis no muestra diferencia estadísticamente significativa entre los tratamientos 1, 2 y 3 , con respecto a la proteína bruta de FVH de maíz chocosito, pues p>0.05 (Gráfica 1).

Por el contrario, de acuerdo con la prueba U de MannWhitney, sí se encontraron diferencias estadísticamente significativas entre la raíz y follaje del FVH de maíz estudiado, en cuanto al porcentaje de proteína bruta pues $\mathrm{p}<0.05$ (Gráfica2).

\section{CONCLUSIONES}

El tiempo óptimo de cosecha del forraje verde hidropónicoFVH es a los 12 días, porque en este tiempo el forraje presenta 
Bioetnia Volumen 6 No 2 (julio-diciembre), 2009

la mayor concentración proteica, pero al mismo tiempo, sobresale en la mayoría de elementos nutricionales requerido por los pollos de engorde.

De otro lado, se destaca el hecho de que la sección de la plántula de maíz con mejores condiciones nutricionales para los pollos de engorde es la pare aérea, que en todos los aspectos presenta mayores niveles nutricionales.

\section{LITERATURA CITADA}

Abadía, A., C. Molina, M. Palacios, F. Palacios. 2002. Evaluación de la diversidad florística y análisis estructural del bosque húmedo tropical de la Estación Ambiental Tutunendo, Quibdó. Medellín: Universidad Nacional de Colombia.

AOAC. 1995. Official methods of analysis association of official analytical chemist. $16^{\text {th }}$ ed. Washington, DC: AOAC.

Carballido, C. 2005. Forraje verde hidropónico. Artículos silvoagropecuarios: Forraje verde hidropónico. (en línea). [fecha de acceso 15 de junio de 2008]. URL disponible en: http://www.ofertasagricolas.cl/articulos/88

Castro, R. 2004. Programas nacional de especies menores. San José: Ministerio de Agricultura y Ganadería.

Espinoza, F., Argenti, P., Urdaneta, G, Araque, C. 2004. Uso del forraje de maíz (Zea mays) hidropónico en la alimentación de toretes mestizos. Instituto Nacional de Investigaciones Agrícolas, Centro Nacional de Investigaciones Agropecuarias. Producción animal. Zootecnia Trop. 22 (4): 303-15.

Huterwal, G. 1960. Hidroponía: cultivo de plantas sin tierra. $3^{\mathrm{a}}$ ed. Buenos Aires: Editorial Hobby; 236 pp.

Instituto de Investigaciones Ambientales del Pacífico. MINGA, 2001. Caracterización de la estación ambiental de Tutunendo, Chocó. Quibdó: IIAP.

Jasca, F. B. 1987. Forraje fertilizante y valor nutritivo. Barcelona: Edit. AEDOS

Job, W. 1999. Informe de actividades. Pereira: Instituto de Investigaciones Ambientales del Pacífico.

Niguez, M.E. 1988. Producción de forraje en condiciones de

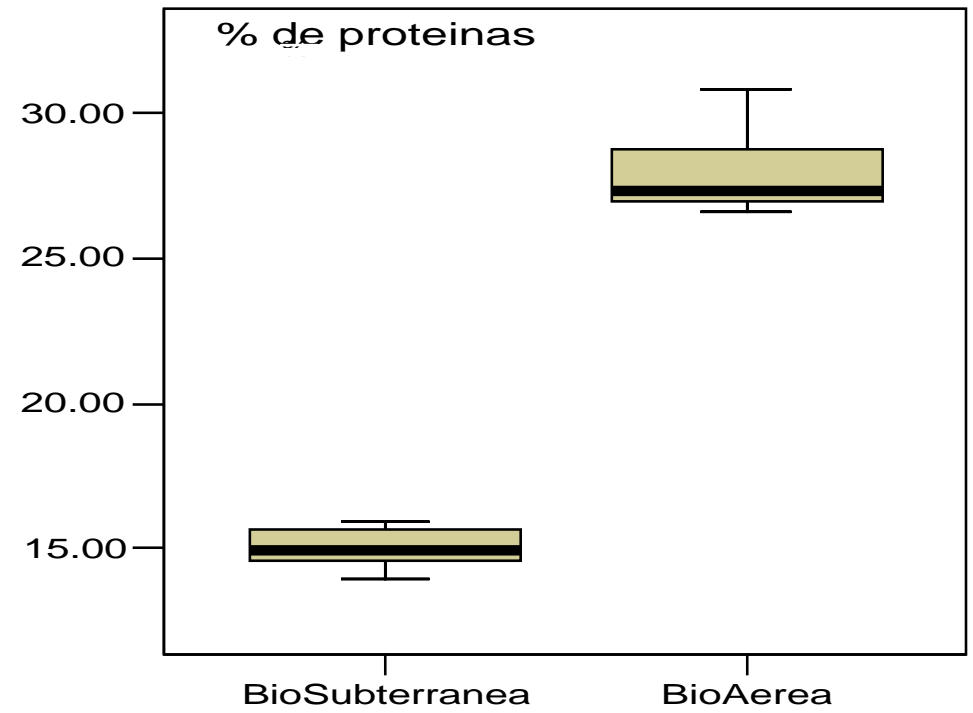

Gráfica 2. Diferencia estadística entre raíz y follaje.

hidroponía II. Selección de especies y evaluación de cebada y trigo. Tesis de grado. Chillán: Universidad de Concepción. Facultad de Ciencias Agropecuarias y Forestales.

Rincón, W. 2002. Adecuación, montaje y producción de la unidad de forraje verde hidropónico. Saravena, Arauca, Colombia. Quibdó: CORPOICA; $3-4,8-11,13 \mathrm{p}$.

Rodríguez, D. A., Tarrillo, O. H. 2003. Producción de forraje verde hidropónico como alternativa de alimento para animales de las zonas afectadas por la ola de frío en el sur del Perú. Agro Enfoque. 133: 53-6.

Tarrillo, O. H. 2002. Producción de forraje verde hidropónico en Arequipa, Perú. Publicado por el Centro de investigación de Hidroponía y Nutrición Mineral de la Universidad Nacional Agraria la Molina. Boletín Informativo $\mathrm{N}^{\circ} 15$ Abril/junio.

Torrijos, G. J. 1976. La cría del pollo de carne broilers. $2^{\mathrm{a}}$ ed. Medellín: Biblioteca Agrícola AEDOS. 